\title{
The management of abdominal wall hernias - in search of consensus
}

\author{
Maciej Pawlak ${ }^{1}$, Kamil Bury², Maciej Śmietański ${ }^{3}$ \\ ${ }^{1}$ Department of General Surgery, Ceynowa Hospital, Wejherowo, Poland \\ ${ }^{2}$ Department of Cardiac and Vascular Surgery, Medical University of Gdansk, Gdansk, Poland \\ 3/I Department of Radiology, Medical University of Gdansk, Gdansk, Poland
}

Videosurgery Miniinv 2015; 10 (1): 49-56

DOI: $10.5114 /$ wiitm.2015.49512

\begin{abstract}
Introduction: Laparoscopic repair is becoming an increasingly popular alternative in the treatment of abdominal wall hernias. In spite of numerous studies evaluating this technique, indications for laparoscopic surgery have not been established. Similarly, implant selection and fixation techniques have not been unified and are the subject of scientific discussion.

Aim: To assess whether there is a consensus on the management of the most common ventral abdominal wall hernias among recognised experts.

Material and methods: Fourteen specialists representing the boards of European surgical societies were surveyed to determine their choice of surgical technique for nine typical primary ventral and incisional hernias. The access method, type of operation, mesh prosthesis and fixation method were evaluated. In addition to the laparoscopic procedures, the number of tackers and their arrangement were assessed.

Results: In none of the cases presented was a consensus of experts obtained. Laparoscopic and open techniques were used equally often. Especially in the group of large hernias, decisions on repair methods were characterised by high variability. The technique of laparoscopic mesh fixation was a subject of great variability in terms of both method selection and the numbers of tackers and sutures used.

Conclusions: Recognised experts have not reached a consensus on the management of abdominal wall hernias. Our survey results indicate the need for further research and the inclusion of large cohorts of patients in the dedicated registries to evaluate the results of different surgical methods, which would help in the development of treatment algorithms for surgical education in the future.
\end{abstract}

Key words: abdominal wall hernia, laparoscopic ventral hernia repair, consensus, experts opinion.

\section{Introduction}

Abdominal wall hernias are one of the most common surgically treated medical conditions worldwide. Although the standards for hernia repair have changed greatly over the last few decades and there have been many studies and debates on this issue, the level of evidence currently available makes it impossible to provide recommendations for management of primary ventral or incisional hernias. Following the example of the European Hernia Society (EHS) in the creation of guidelines on the treatment of inguinal hernia in adult patients [1], today it is of the utmost importance to provide tools for the development of clear

\section{Address for correspondence}

Maciej Pawlak MD, Department of General Surgery, Ceynowa Hospital, 10 Jagalskiego St, 84-200 Wejherowo, Poland,

phone: +48 501492 484, e-mail: maciek.pawlak@wp.pl 
guidelines and level A evidence based medicine (EBM) recommendations for the treatment of ventral hernia.

The choice of method for hernia repair has been thoroughly discussed in the meta-analysis by Sauerland et al., who stated that the laparoscopic technique demonstrated superiority in shortterm results, but any definitive evaluation requires a thorough assessment of recurrence rates and randomised trials with longer observation periods [2]. An interesting possibility to create valid international guidelines is obtaining outcome measurements of abdominal wall hernia repairs around the world. This concept is gaining more and more support, and hence in recent years, several national and international databases such the European Registry of Abdominal Wall Hernias has been developed [3]. However much has been done for the development of guidelines and EBM recommendations, currently we have no clear consensus on that matter.

\section{Aim}

The aim of this study is to determine whether there is a mutual opinion of experts regarding ventral hernia repair and to verify whether there are clear guidelines for the education of surgical techniques for the most common abdominal wall hernias.

\section{Material and methods}

Langer et al. showed that the most important prognostic factor for patients who undergo hernia

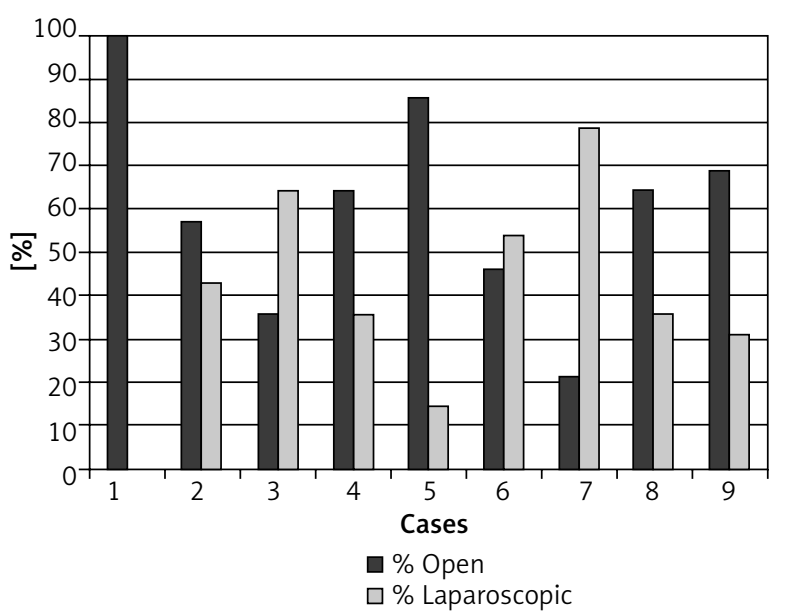

Figure 1. Percentage distribution of laparoscopic operation versus open surgery repair is the surgeon's experience [4]. Taking this into consideration, we decided to ask the most experienced and most eminent representatives of the EHS to develop methods of treatment for primary ventral and incisional abdominal wall hernias. We created a questionnaire consisting of nine clinical cases. During the meeting in Torun, Poland, in 2011, fourteen members of the EuraHS working group were invited to fill in the questionnaire and to briefly describe their recommendations for the management of each abdominal wall hernia.

In our opinion, the proposed cases are among the most common in both primary and post-operative abdominal wall hernias. They are also the most common dilemmas in daily surgical practice. Detailed descriptions, graphic illustrations and questions to the experts are presented in Table I.

\section{Statistical analysis}

All statistical analyses were performed with Statistica Software (StatSoft Inc.). Qualitative data are expressed as frequencies and percentages; descriptive data are shown in tables and figures.

\section{Results}

Fourteen surgeons were presented with the questionnaire. The survey consisted of 9 clinical cases of abdominal wall hernias, both primary and incisional. The questions focused on 3 main issues: surgical access, mesh implants and fixation method.

\section{Open versus laparoscopic}

There was a great diversity among the surgeons regarding the access method. The laparoscopic versus open technique ratio was different depending on the individual case, except for the small umbilical hernia, in which all surgeons were unanimous and chose the open method of operation. The percentage distribution of laparoscopic operations compared to open surgery for each case is presented in Figure 1.

\section{Mesh implants}

In the overwhelming majority of cases, the respondents emphasised the importance of reinforcement of the abdominal wall with mesh implants. However, there were variations in mesh dimension, positioning and fixation method. Table II presents the percentage distribution of technical aspects of mesh placement for the 9 cases. 
Table I. Descriptions and graphic illustrations of the cases presented

\begin{tabular}{|c|c|c|c|}
\hline Case & Description & Figure & Specific questions to the case \\
\hline 1 & $\begin{array}{l}\text { Small primary umbilical } \\
\text { hernia ( } 1 \mathrm{~cm} \text { diameter) }\end{array}$ & $\begin{array}{l}\text { Case } 1 \\
\text { small primary umbilical } \Phi 1 \mathrm{~cm}\end{array}$ & $\begin{array}{l}\text { - The type of operation: open vs. laparoscopic } \\
\text { - The method of strengthening the abdominal } \\
\text { wall } \\
\text { - Mesh implant, diameter and fixation technique }\end{array}$ \\
\hline 2 & $\begin{array}{l}\text { Large primary umbilical } \\
\text { hernia ( } 6 \mathrm{~cm} \text { diameter) }\end{array}$ & $\begin{array}{c}\text { Case } 2 \\
\text { large primary umbilical } \Phi 6 \mathrm{~cm}\end{array}$ & \\
\hline 3 & $\begin{array}{l}\text { Two incisional hernias } \\
\text { above umbilicus } \\
\left(1^{\text {st. }} 3 \mathrm{~cm} ; 2^{\text {nd }}: 5 \mathrm{~cm}\right)\end{array}$ & 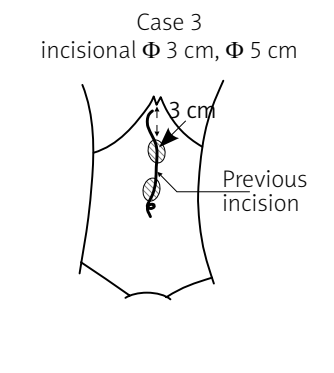 & $\begin{array}{l}\text { - Type of access } \\
\text { - Whether to repair both defects separately or to } \\
\text { cover whole scar area } \\
\text { - Mesh implant, diameter and fixation technique } \\
\text { - technique and defect closure } \\
\text { - mesh placement } \\
\text { In laparoscopic: } \\
\text { - suture fixation } \\
\text { - tackers and the density of fixation }\end{array}$ \\
\hline 4 & $\begin{array}{l}\text { Incisional hernia with } \\
\text { multiple hernia defects } \\
\text { ( } 5 \text { sacks) in the middle } \\
\text { line of the lower } \\
\text { abdomen }\end{array}$ & $\begin{array}{c}\text { Case } 4 \\
\text { lower abdomen }\end{array}$ & $\begin{array}{l}\text { - Type of operation (laparoscopic vs. open) } \\
\text { - Mesh implant, diameter and fixation technique } \\
\text { In laparoscopic repair: } \\
\text { - do experts agree that laparoscopy gives better } \\
\text { insight into the extent of damage to the ab- } \\
\text { dominal wall? } \\
\text { - how to fix the mesh below the pubic bone } \\
\text { In open: } \\
\text { - mesh placement } \\
\text { - whether to do muscle compartment separation }\end{array}$ \\
\hline 5 & $\begin{array}{l}\text { AAA defect - diameter } \\
10 \mathrm{~cm} \text { with multiple } \\
\text { defects in the upper } \\
\text { middle line - Swiss } \\
\text { cheese hernia }\end{array}$ & $\begin{array}{c}\text { Case } 5 \\
\text { AAA max. } 10 \mathrm{~cm}\end{array}$ & $\begin{array}{l}\text { - Type of operation (laparoscopic vs. open) } \\
\text { - Mesh implant, diameter and fixation technique } \\
\text { In laparoscopic repair: } \\
\text { - mesh fixation above the line of the ribs } \\
\text { - suture fixation } \\
\text { - tackers and their locations } \\
\text { In open: } \\
\text { - defect closure } \\
\text { - mesh placement }\end{array}$ \\
\hline
\end{tabular}




\begin{tabular}{|c|c|c|c|}
\hline 6 & $\begin{array}{l}\text { Defect after open } \\
\text { appendectomy - diam- } \\
\text { eter } 10 \mathrm{~cm} \text {. Pararectus } \\
\text { incision and multi-sack } \\
\text { hernia with defined } \\
\text { rings }\end{array}$ & $\begin{array}{l}\text { Case } 6 \\
\text { post ap. acc. max. } 10 \mathrm{~cm}\end{array}$ & $\begin{array}{l}\text { - Type of operation (laparoscopic vs. open) } \\
\text { - Mesh implant, diameter and fixation technique } \\
\text { In laparoscopic repair: } \\
\text { - suture fixation } \\
\text { - tackers and their locations } \\
\text { In open: } \\
\text { - defect closure } \\
\text { - mesh placement }\end{array}$ \\
\hline 7 & $\begin{array}{l}\text { Subcostal hernia }-3 \mathrm{~cm} \\
\text { diameter }\end{array}$ & $\begin{array}{c}\text { Case } 7 \\
\text { subcostal } \Phi 3 \mathrm{~cm}\end{array}$ & $\begin{array}{l}\text { - Clarify technique options } \\
\text { - Mesh diameter and fixation in subcostal area } \\
\text { In laparoscopic repair: } \\
\text { - suture fixation } \\
\text { - tackers and their locations } \\
\text { In open: } \\
\text { - defect closure } \\
\text { - mesh placement }\end{array}$ \\
\hline 8 & $\begin{array}{l}\text { Large subcostal hernia - } \\
7 \mathrm{~cm} \text { diameter }\end{array}$ & $\begin{array}{c}\text { Case } 8 \\
\text { large subcostal } \Phi 7 \mathrm{~cm}\end{array}$ & \\
\hline 9 & $\begin{array}{l}\text { Weakness after open ap- } \\
\text { pendectomy. There was } \\
\text { no defined sack but was } \\
\text { loss of muscle }\end{array}$ & $\begin{array}{c}\text { Case } 9 \\
\text { weaknes (ap. acc.) } \\
\end{array}$ & $\begin{array}{l}\text { - Type of operation (laparoscopic vs. open) } \\
\text { - Mesh implant, diameter and fixation technique } \\
\text { - Muscle flap repair } \\
\text { In laparoscopic repair: } \\
\text { - suture fixation } \\
\text { - tackers and their locations } \\
\text { In open: } \\
\text { - defect closure } \\
\text { - mesh placement }\end{array}$ \\
\hline
\end{tabular}

Right column details the specific questions concerning each case.

In the open surgery group, the Sublay technique was most frequent. When choosing the laparoscopic approach, intraperitoneal on-lay mesh (IPOM) was the method of choice. In addition, the necessity of the component separation method was stressed in cases 3, 4 and 5 .

The diversity of the implant sizes used by the surgeons in each case was noteworthy. The majority of the respondents emphasised having a wide overlap of the mesh covering the defect. The suggested lower limit of the overlap was $5 \mathrm{~cm}$.

\section{Fixation method}

When considering the fixation method, we again found great heterogeneity among surgeons. In all the cases in which the experts recommended the open method, they responded that they would either fix the mesh by non-absorbable sutures or leave the implant unsecured. There was no pattern in the preferred suture placement. One participant highlighted the use of self-fixing Parietex ProGrip ${ }^{T M}$ Mesh.

In contrast, when describing laparoscopic operations, the main focus was on the mesh fixation technique. Tackers and sutures were most popular. Only two surgeons opted for fixation reinforcement with the addition of glue (one in case 2 and one in cases 6 and 7). Table III presents the distribution of fixation methods in each specific case.

\section{Other findings}

In small umbilical hernia repair, it is worth mentioning that 4 surgeons would use local anaesthesia. Furthermore, two surgeons stressed the fact that IPOM operation would be indicated in the obese patients. 
Table II. The percentage distribution of technical aspects of mesh placement for the reported cases

\begin{tabular}{|c|c|c|c|c|c|c|c|}
\hline Case & Onlay [\%] & Sublay [\%] & IPOM [\%] & $\begin{array}{l}\text { IPOM with } \\
\text { TAPP/TEP [\%] }\end{array}$ & $\begin{array}{c}\text { Mesh plug } \\
{[\%]}\end{array}$ & Inlay [\%] & Ramirez [\%] \\
\hline 1 & 17 & 33 & & & 50 & & \\
\hline 2 & & 36 & 57 & & & 7 & \\
\hline 3 & & 29 & 64 & & & & 7 \\
\hline 4 & & 57 & 14 & 21 & & & 7 \\
\hline 5 & 14 & 21 & 14 & & & & 50 \\
\hline 6 & 8 & 38 & 31 & 23 & & & \\
\hline 7 & 7 & 14 & 79 & & & & \\
\hline 8 & 14 & 36 & 36 & & & 14 & \\
\hline 9 & 17 & 42 & 17 & 17 & & 8 & \\
\hline
\end{tabular}

Onlay - the mesh is positioned above the abdominal wall muscles and fascia, behind the subcutaneous fat, Sublay - retromuscular position of the mesh; IPOM - intraperitoneal onlay mesh, TAPP - transabdominal preperitoneal repair, TEP - totally extraperitoneal repair; Inlay - the mesh is positioned in the hernia defect, without overlap, and fixed to the margins of the defect, Ramirez-component separation technique (the Ramirez operation).

Table III. The distribution of fixation methods in each specific case

\begin{tabular}{|lcccccccc|}
\hline Variable & Case 2 & Case 3 & Case 4 & Case 5 & Case 6 & Case 7 & Case 8 & Case 9 \\
\hline Number of laparoscopies & 6 & 9 & 5 & 2 & 7 & 11 & 5 & 4 \\
\hline Single crown & & 3 & 2 & 1 & 3 & 3 & 2 & 1 \\
\hline Double crown & 4 & 3 & 2 & 1 & 2 & 4 & & 2 \\
\hline S.c. + sutures & 1 & 2 & 1 & & 1 & 2 & & \\
\hline d.c. + sutures & 1 & 1 & & & 1 & 2 & 3 & 2 \\
\hline With TAPP/TEPP & & & 3 & & 3 & & & 2 \\
\hline
\end{tabular}

s.c. - single crown, d.c. - double crown, TAPP - transabdominal preperitoneal repair, TEP - totally extraperitoneal repair.

Of note are the cases in which there was a problem of implant fixation to the bony structures. In cases 7 and 8 , there was great variety in the mesh fixation technique in the subcostal area. The respondents were unanimous in terms of taking necessary precautions when fixing the mesh above the rib line. The respondents were divided into three main groups: one would use single sutures $(n=4)$, another group advocated using tackers, and the third $(n=4)$ would not use fixation above the rib line. One respondent supported the use of glue in that area, and one would use running sutures.

In cases of incisional hernias in the lower abdomen $(4,6,9)$, when considering a laparoscopic approach below the pubic bone and cooper ligament, the modification of the IPOM technique with mesh peritonealisation was the most popular.

Interestingly, one of the respondents did not consider muscle weakness after open appendectomy as pathology and was against surgical treatment. Another expert suggested open suture application with non-absorbable sutures. The majority would perform an open procedure with mesh in the Sublay position and muscular defect repair.

\section{Discussion}

Many different techniques are currently used for ventral and incisional hernia repair. The need for a consensus is a leading issue for both practicing surgeons and the surgeons in training. A consensus would make possible a platform for the discussion about algorithms of ventral hernia management as well as improve and unify the education of young surgeons and residents. Furthermore, our patients could obtain the best possible surgical care regardless of the hospital choice.

The indications for performing laparoscopic procedures were not identified in this study. Neverthe- 
less, we noticed that experts were more willing to choose laparoscopic means of operation in cases of medium-sized incisional hernias, such as case 3 , where it was important to assess not only the gap but also the remaining part of the wound closure, and in cases 2, 6 and 7, where the access and implant positioning were more difficult to perform openly. The meta-analyses [2, 5-7] have shown that the short-term outcomes of laparoscopic repair are promising, but we still lack a long-term follow-up meta-analysis that would state the numbers of recurrences and hence also the efficacy of this method. Moreover, we have to keep in mind the drawbacks of laparoscopic ventral hernia repairs (LVHRs), such as increased risk of adhesions, bowel injuries and enterotomies during subsequent operations, as well as increased hospital costs. In our study, experts were generally positive about laparoscopic surgery.

When comparing Onlay and Sublay mesh placement, the recurrence rates in the literature do not differ significantly [8]. In a Cochrane review from 2008, there was not sufficient evidence about which position of the mesh is superior [9]. There was also insufficient evidence to advocate the use of the component separation technique. In our survey, when comparing Onlay vs. Sublay, the retromuscular prosthetic repair (Rives-Stoppa techniques) using nonresorbable polypropylene or polyester mesh was chosen more frequently. Similar opinions can be found in the literature and among hernia surgeons $[8,9]$.

The heterogeneity on the topic of the type and size of mesh as well as the fixation methods, especially when considering laparoscopic approach, reflects the current trends in hernia repair. There are many new products on the market and few studies about the outcomes of their use in patients [10]. In the literature review by La Blanc from 2007, the results showed the benefit of the sole use of tacks, with a recurrence rate of approximately $4 \%$ with the use of sutures and $1.8 \%$ without their use [11]. Even more in favour of the double crown technique are the results of the WoW randomised control trial, in which Muysoms et al. showed that mesh fixing without sutures is superior in terms of the number of recurrences and early and chronic abdominal wall pain [12]. However, the authors state several limitations of their study, such as inclusion of patients only with hernias at a distance from the bony borders of the abdomen and non-standardised mesh types. The implant/fixation issue can be solved by randomized control trials comparing meshes with the use of dedicated tacker systems. Furthermore, we should investigate the structure of the abdominal wall so we can know how to correctly place tackers, especially in the difficult cases. We also need to focus on unifying technical aspects of each procedure. Based on these assumptions is the HAL2010 program, created on the basis of 'Biomechanics of the front abdominal wall as a potential factor leading to recurrence with laparoscopic ventral hernia repair' [13]. The authors propose software that supports decision making in performing IPOM surgery. After loading data on hernia dimension and localisation, the HAL2010 program gives the surgeon information about where to place the mesh, how large the overlap should be, how many tackers or sutures should be used and where to place them. However, this software still needs clinical evaluation and further development.

In the recently published 'Recommendations for reporting outcome results in abdominal wall repair', the Palermo group have proposed guidelines for researchers on ventral hernia management [14]. This was another milestone towards more reliable and standardised studies with good reporting standards and statistical methodology. Multicentre randomised trials are considered the most valuable, but observational studies, such as comparative retrospective studies or noncomparative cohort studies, when conducted properly, can be very useful, especially for the evaluation of abdominal hernia repair. Moreover, those authors mention that registries are a source of important information for health care, as they generate scientific hypotheses and allow researchers to consider safety questions.

Another important publication from Italy was one of the first evidence-based guidelines for laparoscopic ventral incisional hernia repair [15]. The Naples group tried to answer the most concerning questions about the safety and feasibility of the laparoscopic approach in ventral hernia repair. Unfortunately, based on the available literature, the grade of recommendation did not reach $A$ level in any of the chapters presented. Nevertheless, the group managed to raise a number of important issues, such as the establishment of indications for a laparoscopic approach and the preferred preoperative work-up and selection of patients.

Recently published in Surgical Endoscopy were the guidelines for laparoscopic treatment of ventral and incisional abdominal wall hernias (International 
Endohernia Society (IEHS)) [16]. The Bittner's group have taken into consideration the most important aspects of laparoscopic ventral hernia repair. The work was based on a massive quantity of data derived from the most important publications. Therefore the article has been divided into separate parts and each part into sections with meticulously discussed questions on laparoscopic treatment of incisional and ventral hernia. Nevertheless when faced with common clinical cases as presented in our work it might be difficult to find an answer on how to perform the operation and select the patients. The data available are not precise, still we have too few randomized control trails on specific subjects and results derived from National Databases are not considered as a high quality in the Oxfords EBM hierarchy. In the end the most fundamental questions such as indications for surgery were graded $D$, which states that there are no recommendation at all. Again we are informed that it is safe and feasible to do laparoscopy and how to precede if we chose this method of operation, but it is not and should not be our only choice. In the group of our experts there were surgeons also involved in the IEHS guidelines creation, their unanimity reaffirms the lack of consensus. The variance of opinion in both studies was mostly in the technical aspects, and not in well-established principles such as the hernia mesh repair.

We have to keep in mind that there is a difference between EBM, guidelines and everyday clinical practice. Many surgeons simply choose operating methods that suit their skills better. The reasons for that are lack of knowledge and reluctance toward changes. In addition, it is extremely difficult and tedious for every practicing surgeon to search medical databases and do a critical appraisal of each method. Still, in most surgical departments, training is based on the principle of master and his follower. This type of teaching has many benefits, but in our opinion, it has one very important drawback: the successor will perpetuate the mistakes of his master. The modern way of training is based on multicentre internships. It gives trainees the opportunity to see many experienced surgeons at work and to learn from them. This allows them to obtain knowledge about various surgical techniques and gain the ability to think multidimensionally [17-20]. Śmietański, in his article "The influence of carrying out multicentre trials on surgical practice in general surgery departments", showed that only exchange of knowledge and in- ternships in different units, from district to university hospitals, can improve the training of young surgeons [21]. The results of our survey clearly show that even among experts, standardised procedures such as IPOM are performed in various ways. For surgeons willing to adapt new procedures and surgeons in the process of training, information such as the variability of the procedure, depending on the anatomical location of the defect, the type of mesh and the fixation methods are the most essential. Therefore, there is a need for international hernia surgery education programmes, which will improve the quality of professional education in herniology and raise the level of medical service throughout the unified programme of teaching worldwide.

\section{Conclusions}

Experts have not reached a consensus on the management of abdominal wall hernias. Our survey results indicate the need for further research and the inclusion of large patient cohorts in the dedicated registries to evaluate the results of different surgical methods. To date, much effort has been expended to create a common language when describing ventral and incisional hernias, as well as foundations for large projects aimed at establishing recommendations. However, much work remains before we can present definitive algorithms and educational models for hernia surgeons, which makes the discussion among surgeons more important.

\section{Acknowledgments}

We would like to thank to the European Hernia Society and EuraHS board members for their support and participation in our survey, in particular: Ferdinand Kockerlin, Johanes Jeekel, Giampiero Campanelli, Vincenzo Mandala, Ulrich Dietz, Gerard Champaux, Andrew DeBeaux, Agneta Montgomery, Marc Miserez, Uve Klinge, Rogier Simmermacher, Filip Muysoms, Salvador Morales Conde.

\section{Conflict of interest}

The authors declare no conflict of interest.

\section{References}

1. Simons MP, Aufenacker T, Bay-Nielsen M, et al. European Hernia Society guidelines on the treatment of inguinal hernia in adult patients. Hernia 2009; 13: 343-403. 
2. Sauerland S, Walgenbach M, Habermalz B, et al. Laparoscopic versus open surgical techniques for ventral or incisional hernia repair. Cochrane Database Syst Rev 2011; 3: CD007781.

3. Muysoms F, Campanelli G, Champault GG, et al. EuraHS: the development of an international online platform for registration and outcome measurement of ventral abdominal wall hernia repair. Hernia 2012; 16: 239-50.

4. Langer C, Schaper A, Liersch T, et al. Prognosis factors in incisional hernia surgery: 25 years of experience. Hernia 2005; 9 : 16-21.

5. Forbes SS, Eskicioglu C, McLeod RS, Okrainec A. Meta-analysis of randomized controlled trials comparing open and laparoscopic ventral and incisional hernia repair with mesh. Br J Surg 2009; 96: 851-8.

6. Sajid MS, Bokhari SA, Mallick AS, et al. Laparoscopic versus open repair of incisional/ventral hernia: a meta-analysis. Am J Surg 2009; 197: 64-72.

7. Pierce RA, Spitler JA, Frisella MM, et al. Pooled data analysis of laparoscopic vs. open ventral hernia repair: 14 years of patient data accrual. Surg Endosc 2007; 21: 378-86.

8. Israelsson LA, Smedberg S, Montgomery A, et al. Incisional hernia repair in Sweden 2002. Hernia 2006; 10: 258-61.

9. den Hartog D, Dur AHM, Tuinebreijer WE, Kreis RW. Open surgical procedures for incisional hernias. Cochrane Database Syst Rev 2008; 3: CD006438.

10. Grubnik VV, Grubnik AV, Vorotyntseva KO. Laparoscopic repair of incisional and ventral hernias with the new type of meshes: randomized control trial. Videosurgery Miniinv 2014; 9: 145-51.

11. LeBlanc KA. Laparoscopic incisional hernia repair: are transfascial sutures necessary? A review of the literature. Surg Endosc 2007; 21: 508-13.

12. Muysoms F, Vander Mijnsbrugge G, Pletinckx P, et al. Randomized clinical trial of mesh fixation with "double crown" versus "sutures and tackers" in laparoscopic ventral hernia repair. Hernia 2013; 17: 603-12.

13. Śmietański M, Bury K, Tomaszewska A, et al. Biomechanics of the front abdominal wall as a potential factor leading to recurrence with laparoscopic ventral hernia repair. Surg Endosc 2012; 26: 1461-7.

14. Muysoms FE, Deerenberg EB, Peeters E, et al. Recommendations for reporting outcome results in abdominal wall repair: results of a Consensus meeting in Palermo, Italy, 28-30 June 2012. Hernia 2013; 17: 423-33.

15. Cuccurullo D, Piccoli M, Agresta F, et al. Laparoscopic ventral incisional hernia repair: evidence-based guidelines of the first Italian Consensus Conference. Hernia 2013; 17: 557-66.

16. Bittner R, Bingener-Casey J, Dietz U, et al. Guidelines for laparoscopic treatment of ventral and incisional abdominal wall hernias (International Endohernia Society (IEHS)) - Part 1. Surg Endosc 2014; 28: 2-29.

17. Buzink S, Soltes M, Radonak J, et al. Laparoscopic Surgical Skills programme: preliminary evaluation of Grade I Level 1 courses by trainees. Videosurgery Miniinv 2012; 7: 188-92.

18. Laski D, Stefaniak TJ, Makarewicz W, et al. New comprehensive surgical curriculum of pre-graduate surgical education. Videosurgery Miniinv 2013; 8: 200-10.
19. Pielaciński K, Szczepanik AB, Wróblewski T. Effect of mesh type, surgeon and selected patients' characteristics on the treatment of inguinal hernia with the Lichtenstein technique. Randomized trial. Videosurgery Miniinv 2013; 8: 99-106.

20. Bialecki JT, Wieloch MM, Kolomecki K, et al. Single incision approach to totally extraperitoneal inguinal hernia repair. Videosurgery Miniinv 2014; 9: 201-6.

21. Śmietański M, Bigda J, Łukasieẃicz J, et al. The influence of carrying out multicentre trials on surgical practice in general surgery departments. Videosurgery Miniinv 2009; 4: 20-5.

Received: 19.01.2015, accepted: 12.02.2015. 